\title{
Neuroblast Division during Migration toward the Ischemic Striatum: A Study of Dynamic Migratory and Proliferative Characteristics of Neuroblasts from the Subventricular Zone
}

\author{
Rui Lan Zhang, ${ }^{1}$ Yvonne LeTourneau, ${ }^{1}$ Sara R. Gregg, ${ }^{1}$ Ying Wang, ${ }^{1}$ Yier Toh, ${ }^{1}$ Adam M. Robin, ${ }^{1}$ Zheng Gang Zhang, ${ }^{1}$ \\ and Michael Chopp ${ }^{1,2}$ \\ ${ }^{1}$ Neurology Department, Henry Ford Health Sciences Center, Detroit, Michigan 48202, and 2Physics Department, Oakland University, Rochester, Michigan \\ 48309
}

Ischemic stroke induces neurogenesis in the subventricular zone (SVZ), and newly generated neurons in the SVZ migrate toward the ischemic boundary. However, the characteristics of migrating SVZ cells have not been investigated after stroke. Using time-lapse imaging in both SVZ cells and organotypic brain slice cultures, we measured the dynamics of SVZ cell division and migration of adult rats subjected to stroke. In normal brain slices, SVZ cells primarily migrated dorsally and ventrally along the lateral ventricular surface. However, in stroke brain slices, SVZ cells migrated laterally toward the striatal ischemic boundary. Cultured stroke-derived SVZ cells exhibited a significant $(p<0.01)$ increase in the migration distance $(212 \pm 21 \mu \mathrm{m})$ compared with the nonstroke-derived SVZ cells $(97 \pm$ $12 \mu \mathrm{m})$. Migrating stroke-derived SVZ cells spent significantly $(p=0.01)$ less time in cytokinesis $(0.63 \pm 0.04 \mathrm{~h})$ compared with the time $(1.09 \pm 0.09 \mathrm{~h})$ for nonstroke-derived SVZ cells. Newborn cells with a single leading process exhibited fast migration $(7.2 \pm 0.8 \mu \mathrm{m} / \mathrm{h})$, and cells with multiple processes showed stationary migration $(3.6 \pm 0.8 \mu \mathrm{m} / \mathrm{h})$. Stroke SVZ daughter cells further divided during their migration. The morphology of doublecortin (DCX)-positive cells in fixed brain sections resembled those observed in cultured newborn cells, and the DCX-positive cells proliferated in the ischemic striatum. Collectively, the present study suggests that stroke promotes cytokinesis of migrating neuroblasts, and these cells migrate toward the ischemic striatum with distinct migratory behaviors and retain the capacity for cell division during migration.

Key words: migration; neurogenesis; neuroblast; proliferation; stroke; subventricular zone

\section{Introduction}

In the postnatal rodent subventricular zone (SVZ), neural progenitor cells migrate radially into the overlying white matter and cortex to give rise to astrocytes and oligodendrocytes (Levison and Goldman, 1993; Suzuki and Goldman, 2003), whereas throughout adult life, neural progenitor cells travel the rostral migratory stream (RMS), as chains through tunnels formed by astrocytes, to the olfactory bulb where they differentiate into granule and periglomerular neurons (Doetsch et al., 1997; Luskin et al., 1997; Garcia-Verdugo et al., 1998). The majority of neural progenitor cells within the migratory pathway are neuroblasts expressing doublecortin (DCX) or $\beta$-tubulin III (Tuj1). Neuroblasts maintain the ability to divide during migration in the RMS (Menezes et al., 1995; Doetsch et al., 1997; Feng and Walsh, 2001).

Occlusion of the middle cerebral artery (MCA) results in increases in neurogenesis in the SVZ, and neuroblasts in the SVZ

\footnotetext{
Received Nov. 15, 2006; revised Jan. 3, 2007; accepted Jan. 4, 2007.

This work was supported by National Institute of Neurological Disorders and Stroke Grants P01 NS23393, P01 NS42345, R01 NS38292, and R01 HL64766. We thank Dr. Me Lu and Cindi Roberts for performance of statistical analysis and immunostaining, respectively.

Correspondence should be addressed to Dr. Michael Chopp, Neurology Research Building, Room 3056, Henry Ford Health Sciences Center, 2799 West Grand Boulevard, Detroit, MI 48202. E-mail: chopp@neuro.hfh.edu.

DOI:10.1523/JNEUROSCI.4969-06.2007

Copyright $\odot 2007$ Society for Neuroscience $\quad$ 0270-6474/07/273157-06\$15.00/0
}

migrate toward the ischemic boundary regions of the striatum and cerebral cortex, indicating that ischemic stroke redirects the neural progenitor cell migratory pathway (Arvidsson et al., 2002; Parent et al., 2002; Jin et al., 2003; Zhang et al., 2004a). When they reach the ischemic boundary region, migrating neuroblasts aggregate into clusters. Thereafter, neuroblasts in these clusters disperse and these cells differentiate into striatal neurons, suggesting that new neurons generated by progenitor cells replenish damaged neurons (Lindvall et al., 2004; Zhang et al., 2004a; Yamashita et al., 2006). This process involves the tight coordination of cell proliferation, cell-cycle exit, initiation of neuronal differentiation, and cell migration.

Studying migratory and proliferative behaviors of neuroblasts in the stroke brain is important for understanding mechanisms that regulate stroke-induced neurogenesis. Accordingly, using time-lapse microscopy, we investigated the migratory behavior and the proliferative potential of neural progenitor cells in the SVZ of the adult rat subjected to embolic MCA occlusion. Our in vitro and in vivo data indicate that neuroblasts in the SVZ migrate toward the ischemic striatum with distinct migratory behaviors and retain the capacity for cell division during migration.

\section{Materials and Methods}

All experimental procedures have been approved by the Institutional Animal Care and Use Committee of Henry Ford Hospital (Detroit, MI). 
Animal model of stroke. Male Wistar rats (3-4 months of age) were used. The MCA was occluded by placement of an embolus at the origin of the MCA (Zhang et al., 1997).

Neurospheres. SVZ cells were harvested from nonstroke rats and from rats at $7 \mathrm{~d}$ after MCA occlusion (Morshead et al., 1994; Chiasson et al., 1999; Zhang et al., 2004b). The time point of $7 \mathrm{~d}$ after MCA occlusion was selected based on findings that in this model, stroke-induced neurogenesis peaked $7 \mathrm{~d}$ after MCA occlusion (Zhang et al., 2001, 2004b). The cells were cultured in medium containing $20 \mathrm{ng} / \mathrm{ml}$ basic fibroblast growth factor (bFGF) and epidermal growth factor (EGF; R \& D Systems, Minneapolis, MN) at a cell density of 10,000 cells/ml. The generated primary neurospheres were passaged by mechanical dissociation and reseeded as single cells at a density of 20,000 cells $/ \mathrm{ml}$ in bFGF- and EGF-containing medium (passage 1 cells). Passage 1 to passage 3 cells were used in the present study (Zhang et al., 2004b). A single neurosphere $(\sim 100 \mu \mathrm{m}$ diameter $)$ was embedded in reduced-growth factor medium containing Matrigel ( $40 \mu \mathrm{l}$; BD Biosciences, Franklin Lakes, NJ), with medium containing bFGF and EGF for time-lapse microscopic imaging.

Organotypic brain slice culture. To label SVZ cells, the animal was anesthetized with $1.0-1.5 \%$ halothane and mounted in a Kopf stereotaxic frame (model 51603; Stoelting, Wood Dale, IL). DiI ( $1 \mu \mathrm{l}$ ) was injected into the lateral ventricle of the right hemisphere over a 2 min period using a $10 \mu \mathrm{l}$ syringe (25 gauge; Hamilton, Reno, NV) at the following coordinates, calculated from bregma (in $\mathrm{mm}$ ): anteroposterior, 0.2 ; mediolateral, 2.5 ; depth, 5.0 (Paxinos and Watson, 1986). One day after the injection, nonstroke $(n=3)$ and 7-d-stroke rats $(n=3)$ were killed. The procedure used for organotypic slice culture assay was based on published protocols (Miyata et al., 2002). When removed from the skull, the brain was immediately immersed in ice-cold HBSS (Invitrogen, San Diego, CA) at $\mathrm{pH} 7.2$ for $3 \mathrm{~min}$. A 4-mm-thick coronal brain section between the level of bregma $2.7 \mathrm{~mm}$ and bregma $-1.3 \mathrm{~mm}$ was used for organotypic brain slice culture (Paxinos and Watson, 1986), which includes the entire territory supplied by the MCA (Zhang et al., 1997). The coronal sections (300 $\mu \mathrm{m}$ thick) were cut by a vibratome, and brain slices were placed in a six-well plate with one slice per well. Brain tissue was kept in ice-cold HBSS during these procedures. The brain slice was then embedded in a Cellmatrix gel $(200 \mu$ l, type 1-A; Nitta Gelatin, Osaka, Japan) and incubated for $1 \mathrm{~h}$ with brain slice medium containing the following: DMEM/F-12, $25 \mu \mathrm{g} / \mathrm{ml}$ insulin, $100 \mu \mathrm{g} / \mathrm{ml}$ APOtransferrin, $20 \mathrm{~nm}$ progesterone, $30 \mathrm{~nm}$ sodium selenate, $60 \mu \mathrm{M} \mathrm{pu}$ trescine, $10 \mathrm{ng} / \mathrm{ml} \mathrm{EGF,} 10 \mathrm{ng} / \mathrm{ml}$ bFGF, 5\% horse serum, 5\% fetal calf serum, $1 \%$ penicillin-streptomycin, $1 \%$ sodium bicarbonate, and $0.33 \%$ HEPES (Miyata et al., 2002). After that, brain slices were ready for timelapse microscopic studies.

Time-lapse microscopy. Cultured neurospheres or organotypic brain slices were incubated in a stage top chamber with $5 \% \mathrm{CO}_{2}$ at $37^{\circ} \mathrm{C}$ (LiveCell Control Unit), which was placed on the stage of a Nikon (Tokyo, Japan) TE2000-U Inverted Microscope equipped with a motorized z-stage. A $10 \times$ objective with $1.5 \times$ electronic zoom was used for acquiring images. Bright-field images were acquired for neurospheres, whereas fluorescent field images were obtained for brain slices with excitation and
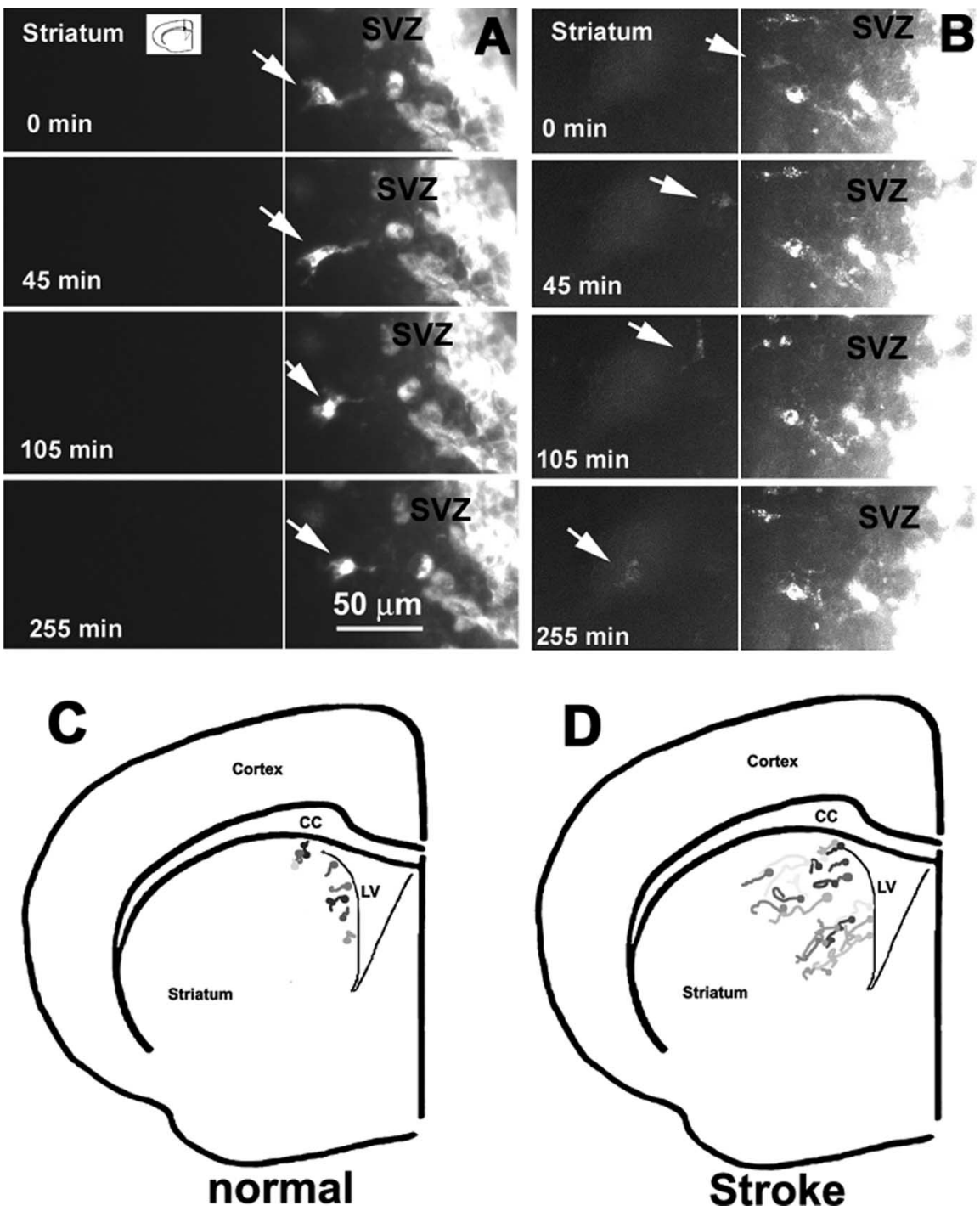

Figure 1. Time-lapse imaging of Dil-labeled cells in living brain coronal slices. The inset in $A$ indicates coronal slices obtained at the nonstroke $(\boldsymbol{A})$ or stroke $(\boldsymbol{B})$ brain slice. Dil-labeled SVZ cells were localized to the SVZ at time $0(\boldsymbol{A}, \boldsymbol{B})$. In a nonstroke-derived brain slice, beled cells within the SVZ migrated dorsally and ventrally $(\boldsymbol{A}$, arrows; $\boldsymbol{C}$, whereas labeled SVZ cells migrated laterally toward the striatum VVZ respectively. Each color in Cand D represents one SVZ cell, and data are a summation of three individual observations from nonstroke $(n=$ $3)$ and stroke $(n=3)$ rats. CC, Corpus callosum; LV, lateral ventricle.

emission filters at 546 and $585 \mathrm{~nm}$, respectively, at $0.5 \mathrm{~ms}$ exposure times. A stack of images (30 images with a $5 \mu \mathrm{m}$ step in $z$-axes) was acquired at 15 min intervals for a total of $20 \mathrm{~h}$ using a CCD camera (CoolSnap, 5000) and MetaView software (Universal Imaging, West Chester, PA).

Immunohistochemistry. Immunostaining for fixed brain coronal sections were performed according to a published protocol (Zhang et al., 2004b). Goat anti-DCX (1:200; Santa Cruz Biotechnology, Santa Cruz, CA) was used as a marker for migrating neuroblasts, and mouse antibromodeoxyuridine (BrdU) (1:100; Boehringer Mannheim, Indianapolis, IN) was used as an index of proliferating cells. Doubleimmunofluorescent images were acquired using Zeiss (Oberkochen, Germany) laser-scanning confocal microscopy (LSM 510 NLO).

Quantification of SVZ cell motility. Cell migration speed and distances were analyzed off-line by tracing individual cells at different levels and times using Universal Imaging MetaMorph software. Subsequently, migratory values were statistically analyzed across treatment groups.

Statistical analysis. The measurements of migration distance and speed were presented as mean \pm SE. Significant differences between stroke and 

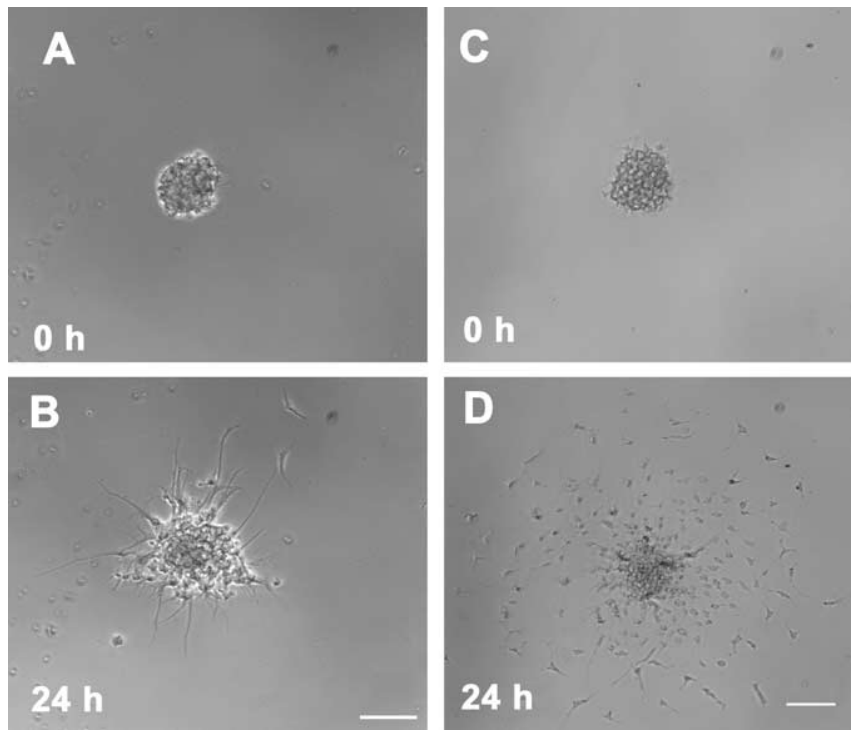

Figure 2. Migration of SVZ cells out of neurospheres. A single neurosphere derived from nonstroke $(\boldsymbol{A}, \boldsymbol{B})$ or stroke $(\boldsymbol{C}, \boldsymbol{D})$ SVZ cells was placed in the Matrigel. After $24 \mathrm{~h}$ in the Matrigel, SVZ cells migrated out of the neurosphere $(\boldsymbol{B}, \boldsymbol{D} ; t=24 \mathrm{~h})$ compared with cells from time $0(\boldsymbol{A}$, $\boldsymbol{C} ; t=0 \mathrm{~h})$. More SVZ cells migrated out of the stroke-derived neurospheres $(\boldsymbol{D})$ than the cells out of the nonstroke-derived neurospheres $(\boldsymbol{B})$, and stroke-derived SVZ cells exhibited distant migration (D). Scale bars, $10 \mu \mathrm{m}$.
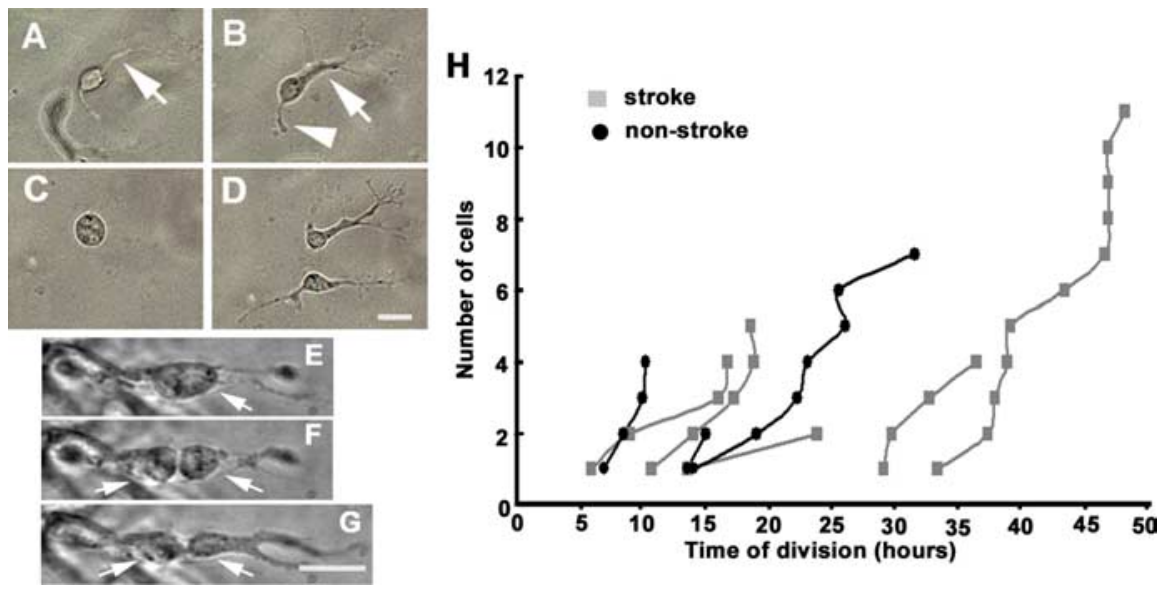

Figure 3. Division of migrating SVZ cells. $A, B$, An individual cell migrated out of the stroke neurosphere had leading $(A, B$, arrows) and tailing processes ( $\boldsymbol{B}$, arrowhead). $\boldsymbol{C}, \boldsymbol{D}$, This cell became round $(\boldsymbol{C})$ and then divided into two daughter cells $(\boldsymbol{D})$. $\boldsymbol{E}-\boldsymbol{G}$, A cell $(\boldsymbol{E}$, arrow) within a process extended from the nonstroke neurosphere divided into two daughter cells $(\boldsymbol{F}, \boldsymbol{G}$, arrows). $\boldsymbol{H}$, Distribution of total dividing cells during a $48 \mathrm{~h}$ experimental period, and each point represents a cell division. Scale bars, $10 \mu \mathrm{m}$.

nonstroke groups were analyzed using a Student's $t$ test. The migration patterns of divided daughter cells were compared using a $\chi^{2}$ test. Statistical significance was detected if $p<0.05$.

\section{Results}

Ischemic stroke promotes SVZ cell migration and directs SVZ cell migration toward the ischemic striatum

Ischemic stroke induces SVZ cell migration toward the ischemic cortex and striatum (Arvidsson et al., 2002; Parent et al., 2002; Jin et al., 2003; Zhang et al., 2004b). To dynamically examine the behavior of SVZ cell migration, we performed time-lapse imaging on living brain coronal slices. DiI was injected into the lateral ventricle to label SVZ cells $1 \mathrm{~d}$ before brain slices were obtained. Migration of DiI-labeled SVZ cells in brain slices was imaged during a $20 \mathrm{~h}$ period. In normal brain slices, SVZ cells primarily migrated dorsally and ventrally along the lateral ventricular surface and never migrated laterally into the striatum (Fig. $1 A, C$ ) which is consistent with previous studies in neonatal rat SVZ cells (Suzuki and Goldman, 2003). However, in stroke brain slices, SVZ cells migrated laterally toward the striatal ischemic boundary region with time (Fig. $1 B, D$ ). A few cells migrated away from the SVZ and later migrated back toward the SVZ (Fig. 1D). Migration of SVZ cells toward the cortex was not detected in stroke brain slices (Fig. 1D). To examine whether stroke SVZ cells intrinsically increase migration, we seeded a single neurosphere derived from SVZ cells from adult normal rats or rats subjected to stroke in Matrigel and measured the migration distance of cells out of the neurosphere $24 \mathrm{~h}$ after incubation. Stroke and nonstroke SVZ cells radially migrated out of neurospheres during this $24 \mathrm{~h}$ period (Fig. 2). Stroke SVZ cells exhibited a significant increase in the migration distance $(212 \pm 21 \mu \mathrm{m} ; n=32$ neurospheres derived from 12 rats) compared with the distance for nonstroke SVZ cells ( $97 \pm 12 \mu \mathrm{m} ; n=32$ neurospheres derived from 16 rats) (Fig. 2). Collectively, the brain slice data suggest that stroke changes the brain microenvironment to direct SVZ cell migration toward the ischemic region, and stroke also alters intrinsic SVZ cell migratory behavior, which is independent of the brain microenvironment.

\section{Migrating SVZ cells divide, and daughter cells have distinct migratory patterns}

To further measure behaviors of SVZ cell proliferation and migration, we performed time-lapse microscopic imaging on individual neurospheres seeded in the Matrigel during a $48 \mathrm{~h}$ experimental period. Cells migrated out of neurospheres either as individual cells (Fig. $3 A, B$ ) or as cells guided by processes extending from neurospheres (Fig. 3E). Individual SVZ cells migrated out of the neurosphere with leading and tailing processes (Fig. $3 A, B$ ) A leading process extended from the soma in the direction of progenitor cell migration (Fig. 3A,B). Morphology of these progenitor cells resembled migrating neurons observed in the ventricular zone of embryonic development (Edmondson and Hatten, 1987). During migration, some cells retracted their external processes and became round (Fig. 3C). Then, the rounded cell divided into two daughter cells (Fig. 3D). The time for a cell to complete cytokinesis starting from rounding was $0.63 \pm 0.04 \mathrm{~h}$ in stroke SVZ cells, which was significantly ( $p=0.01)$ shorter than the time spent for nonstroke SVZ cell division $(1.09 \pm 0.09 \mathrm{~h})$. Mitotic spindle rotation before SVZ cell division was observed (supplemental movie 1, available at www.jneurosci.org as supplemental material). Two daughter cells underwent a second division in stroke neurospheres, which was not detected in nonstroke neurospheres (supplemental movie $2 a, b$, available at www.jneurosci.org as supplemental material). In nonstroke neurospheres, cell division occurred during the first $30 \mathrm{~h}$, whereas cell division was observed during the entire experimental period $(48 \mathrm{~h})$ for stroke neurospheres (Fig. $3 \mathrm{H}$ ). We observed that two and five cells divided within processes extended from the nonstroke and stroke neurospheres, respectively (Fig. 3F, G) 
There were three different migratory behaviors of daughter cells after individual cell division. In type 1 fast migration, a daughter cell with a single polar shape migrated rapidly away from the neurosphere with a speed of $7.07 \pm 0.78 \mu \mathrm{m} / \mathrm{h}$ in stroke and $5.53 \pm 0.42 \mu \mathrm{m} / \mathrm{h}$ in nonstroke SVZ cells $(p>0.05)$, whereas a daughter cell with a bipolar shape paused for a while after division and resumed migration away from the neurosphere with a speed of $4.51 \pm 0.54 \mu \mathrm{m} / \mathrm{h}$ in stroke and $4.15 \pm$ $0.23 \mu \mathrm{m} / \mathrm{h}$ in nonstroke SVZ cells $(p>$ 0.05 ) (Fig. $4 A, B$ ). In type 2 stationary migration, after division, both daughter cells with multiple processes were stationary and migrated a very short distance with an average speed of $3.59 \pm 0.77$ and $3.45 \pm$ $1.93 \mu \mathrm{m} / \mathrm{h}$ in stroke and nonstroke SVZ cells, respectively $(p>0.05)$ (Fig. $4 C, D)$. In type 3 reversed migration, one daughter cell with a unipolar process migrated away from the neurosphere, whereas another daughter cell with a bipolar shape reversed its polarity and migrated toward the neurosphere (Fig. 4E; Table 1). The percentage of cells in each type of migration was not significantly different $(p>0.05)$ between cells from stroke and nonstroke neurospheres (Table 1).

To examine whether migrating and proliferative behaviors of neuroblasts observed in vitro are present in vivo, immunostaining with an antibody against DCX, a marker for migrating neuroblasts, was performed on brain coronal sections of rats subjected to stroke $(n=7)$. DCXpositive cells in the ipsilateral SVZ and striatum had different morphologies either with a leading process toward the ischemic boundary region or round shape (Fig. 5B,D,F), resembling morphologies of migrating cultured SVZ cells (Fig. $5 A, C, E)$. We also found two roundshaped DCX-positive cells next to each other (Fig. $5 \mathrm{H}$ ), suggesting that these two DCX-positive cells are two daughter cells, as we have shown in cultured SVZ cells (Fig. $5 G$ ). To further confirm that migrating neuroblasts divide in vivo, $\mathrm{BrdU}$ was injected, and rats were killed $2 \mathrm{~h}$ after BrdU injection $(n=3)$. Double immunostaining revealed that some DCXpositive cells in the ipsilateral striatum (Fig. $5 I$, green) were BrdU immunoreactive (Fig. 5I, red), indicating that migrating neuroblasts divide in vivo.

\section{Discussion}

The present study provides direct in vitro evidence that migrating adult SVZ cells divide, stroke SVZ cells exhibit substantially more rapid division than SVZ cells from a normal brain, and daughter cells exhibit distinct migratory behaviors. Moreover, in vivo data show that the morphology of DCX-positive cells resembled in vitro cellular morphology with fast migratory behaviors and that DCX-positive cells divided within the ischemic striatum. Thus,
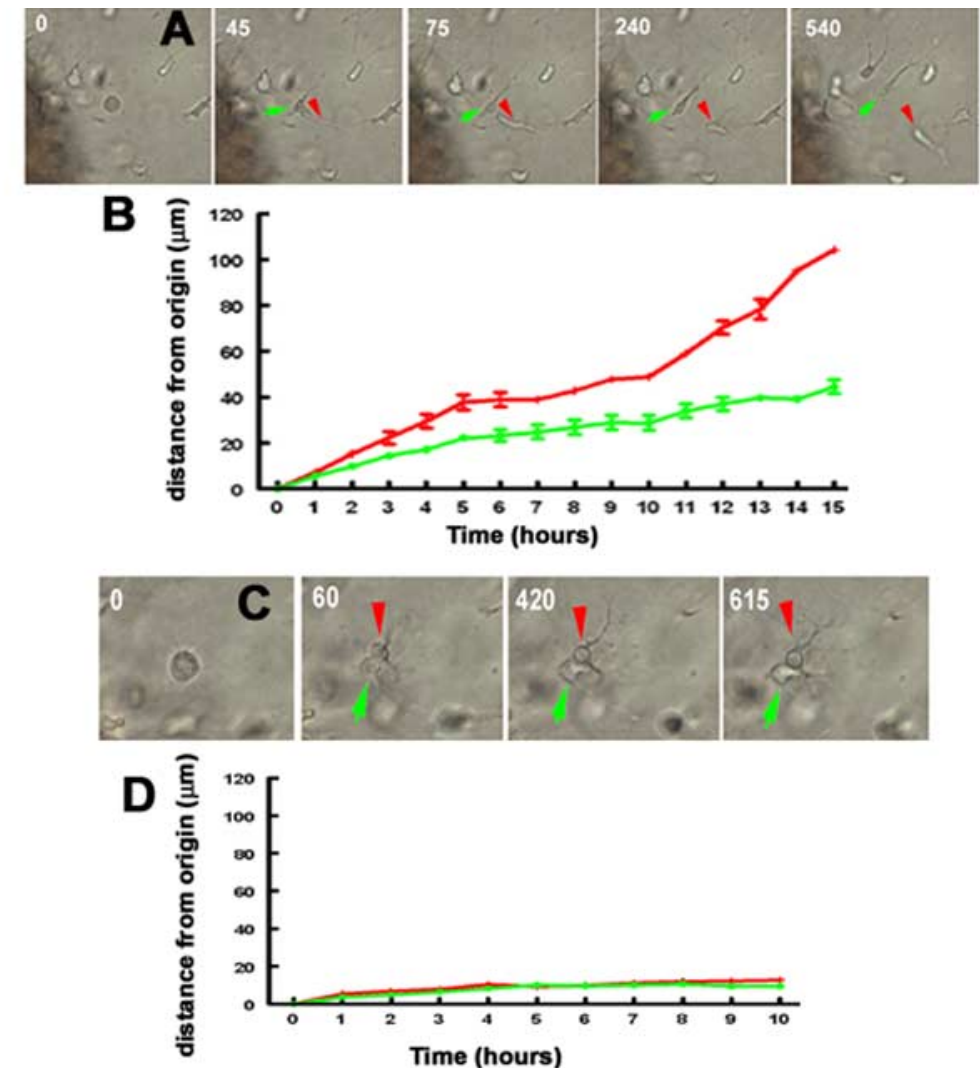

Time (hours)
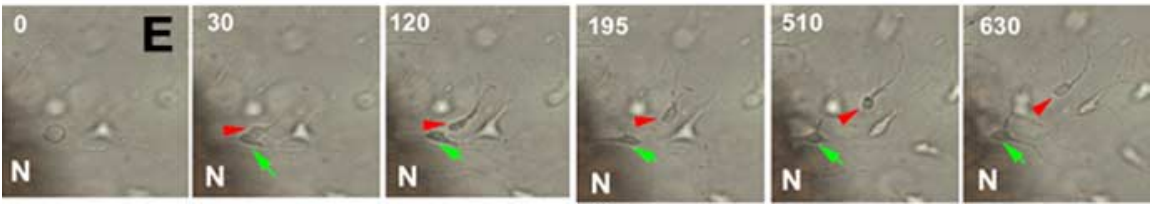

Figure 4. Time-lapse imaging of daughter cell migration. $\boldsymbol{A}$, Fast migration of daughter cells from a representative stroke neurosphere. After cell division, one daughter cell had a bipolar shape (green arrow) and the other had a unipolar shape (red arrowhead). The unipolar daughter cell (red arrowhead) rapidly migrated away from the neurosphere. The bipolar daughter cell ions, which were derived from the total of nonstroke- and stroke-derived daughter cells. Red and green lines represent unipolar . cell marked in C. $\boldsymbol{E}$, Reverse migration direction of daughter cells. The bipolar daughter cell (green arrow) reversed its polarity and migrated toward the neurosphere (N). Numbers in $\boldsymbol{A}, \boldsymbol{C}$, and $\boldsymbol{E}$ are minutes.

Table 1. Distribution of daughter cell migration patterns for individual dividing cells

\begin{tabular}{lcll}
\hline & \multicolumn{3}{l}{ Migration patterns } \\
\cline { 2 - 4 } Parent cells & Fast & Stationary & Reversed \\
\hline Nonstroke $(n=12)$ & $5(42 \%)$ & $2(17 \%)$ & $5(42 \%)$ \\
Stroke $(n=21)$ & $12(57 \%)$ & $6(29 \%)$ & $3(14 \%)$ \\
\hline
\end{tabular}

Parent cells were detected from individual neurospheres (nonstroke, $n=3$; stroke, $n=5$ ).

our data indicate that stroke promotes adult neuroblast division during migration toward the ischemic striatum.

In the SVZ of the adult rodent, type A cells correspond to proliferating, migrating neuroblasts (Doetsch et al., 1997). Using a BrdU-labeling protocol in the neonatal rat, Luskin et al. (1997) suggest that neuroblasts originate from the SVZ and divide within the RMS as they migrate to the olfactory bulb (Menezes et al., 1995). Our time-lapse microscopic results provided, for the first time, direct evidence that adult SVZ cells divide when they 

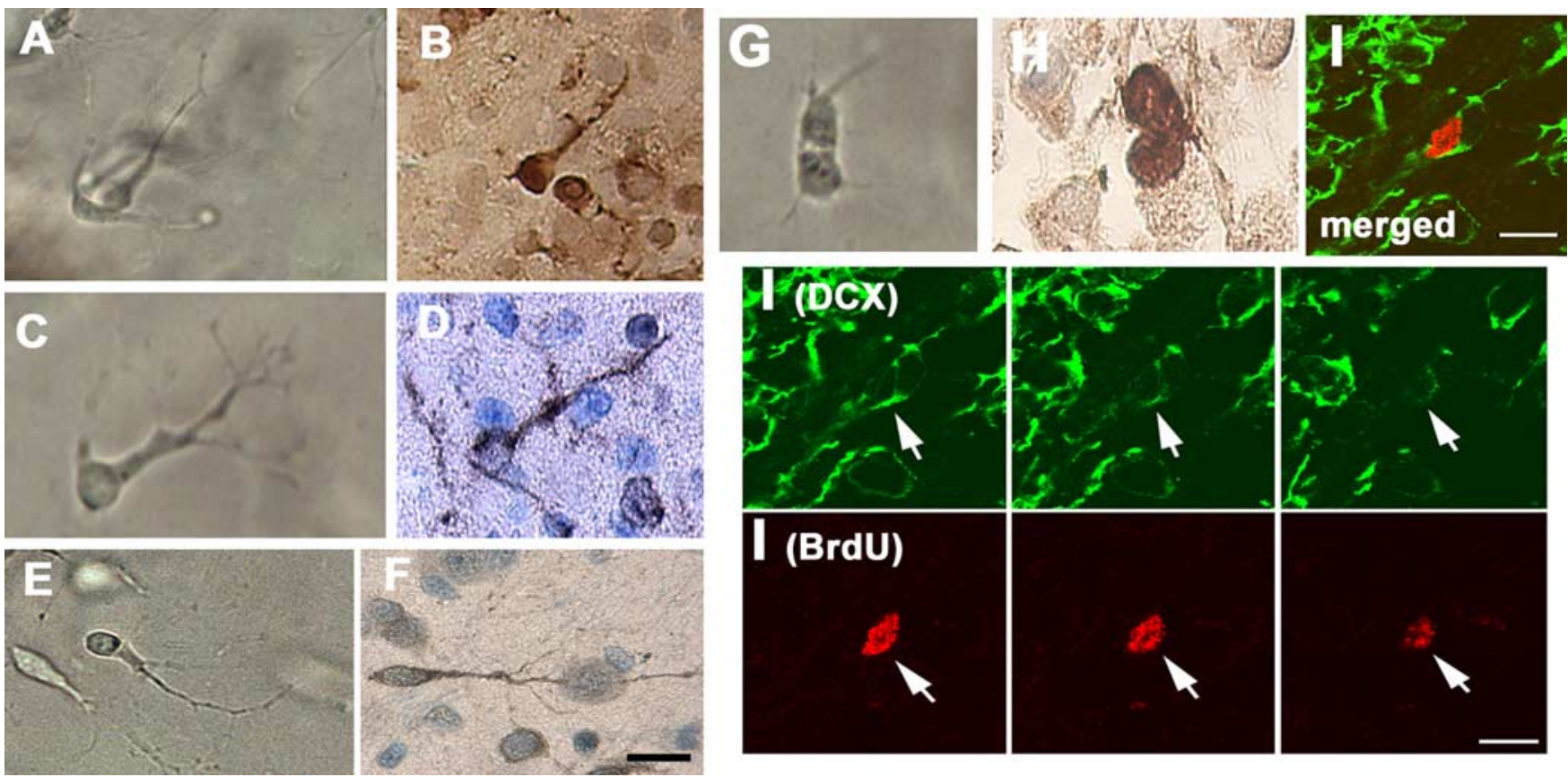

Figure 5. Dividing DCX-positive cells. $\boldsymbol{A}-\boldsymbol{H}$, In vitro morphology of daughter cells $(\boldsymbol{A}, \boldsymbol{C}, \boldsymbol{E}, \boldsymbol{G})$, which were mirrored by in vivo morphology of DCX-positive cells ( $\boldsymbol{B}, \boldsymbol{D}, \boldsymbol{F}, \boldsymbol{H})$. $\boldsymbol{I}$, Confocal images show that a DCX-positive cell (merged, green) in ischemic striatum was BrdU positive (merged, red). Z-stacks of DCX (green) and BrdU (red) immunoreactivity, at $1 \mu \mathrm{m}$ intervals, are shown. Scale bars, $10 \mu \mathrm{m}$.

migrate out of the neurosphere. Neuroblasts form chains when they migrate in the RMS, and the chains are ensheathed by astrocytes (Doetsch et al., 1997; Luskin et al., 1997; Wichterle et al., 1997). In parallel, we observed that SVZ cells divided within a glial process extending from the neurosphere. In addition, timelapse data revealed that individual SVZ cells migrating out of the neurosphere exhibit a bipolar morphology, which resembles migrating neuroblasts (Menezes et al., 1995; Wichterle et al., 1997). During migration, these individual cells divide. Stroke SVZ cells spent significantly less time in cytokinesis compared with nonstroke SVZ cells, suggesting that stroke SVZ cells have a shorter cell-cycle length. During the experimental period (48 h), stroke daughter cells further divided, which was not detected in nonstroke daughter cells, suggesting that stroke daughter cells do not exit the cell cycle. The presence of growth factors in cultured SVZ cells could facilitate neural progenitor cell proliferation. However, in vivo stroke reduces the length of the SVZ cell cycle and increases the number of SVZ cells within the cell cycle (Zhang et al., 2006). Double immunostaining on brain coronal sections shows that migrating neuroblasts identified by DCX-positive cells in the ischemic striatum were proliferating cells labeled by BrdU. A single injection of BrdU labels a cohort of SVZ cells that are in S phase at the time of the injection (Morshead et al., 1994; Zhang et al., 2006). Thus, these DCX- and BrdU-positive cells are likely migratory neuroblasts that undergo cell proliferation in the striatum because these animals were killed $2 \mathrm{~h}$ after the injection. A recent study demonstrates that neuroblasts localized to the ischemic striatum are derived primarily from the SVZ (Yamashita et al., 2006). Together, these data suggest that neuroblasts divide during migration from the SVZ toward the ischemic striatum. Moreover, the morphology of migrating neuroblasts in the ischemic striatum resembled that of in vitro migrating cells, suggesting that migrating neuroblasts are present in the living brain after stroke. Therefore, our in vitro assay may provide a means of investigating migratory and proliferative behaviors of SVZ cells.
Stroke promotes SVZ cell migration toward the ischemic boundary region (Arvidsson et al., 2002; Parent et al., 2002; Jin et al., 2003; Zhang et al., 2003, 2004a). However, migratory characteristics of SVZ cells after stroke have not been established. We provide the first direct evidence that cultured stroke SVZ cells substantially increased their migratory distance compared with nonstroke SVZ cells, indicating that molecules that regulate cell motility triggered by stroke are retained after cell isolation from the SVZ niche. Candidate molecules include stromal cell-derived factor-1 (CXCL12) and its receptor CXCR4, and matrix metalloproteinases (MMPs), which have been shown to regulate neural progenitor cell migration after stroke (Imitola et al., 2004; Lee et al., 2006; Robin et al., 2006; Thored et al., 2006; Wang et al., 2006). Different migratory behaviors of SVZ cells were also detected in brain slices. Our findings in the nonstroke-derived brain slice, that adult SVZ cells only moved within the SVZ, are consistent with published studies in postnatal rats, in which SVZ cells do not migrate to the striatum (Suzuki and Goldman 2003). However, after stroke, SVZ cells migrated toward the ischemic striatum but not the cortex, indicating that in addition to increases in migratory capability, SVZ cells change their migratory direction after stroke. We and others have demonstrated that chemokines, such as CXCL12, MMP2, and MMP9 generated in the ischemic boundary, attract neuroblasts migrating toward the ischemic boundary region (Imitola et al., 2004; Lee et al., 2006; Robin et al., 2006; Thored et al., 2006; Wang et al., 2006). Thus, stroke promotes neuroblast motility via niche-dependent and -independent pathways.

We found that cultured newborn cells exhibited distinct migratory behaviors after cell division. Newborn cells with a single leading process move fast, whereas cells with multiple processes exhibited slower movements. Some newborn cells with bipolar shape showed bidirectional movements by reversing their polarity, which has been reported in embryonic brain slices (Noctor et al., 2004). During cortical neurogenesis, the majority of neurons in the SVZ reverse their polarity to move toward the ventricular 
zone before changing their directions to migrate into the cortex (Noctor et al., 2004). Our finding of bidirectional movement of divided daughter cells suggests that adult neural progenitor cells could inherit migratory behaviors of embryonic neural progenitor cells. Stroke reduced the bidirectional movement population (14\%) compared with the nonstroke population (42\%), although a statistical significance was not achieved. It is not known whether stroke severity affects migratory patterns of divided daughter cells because neurospheres used in the present study were pooled from three to four rats. Additional studies are warranted.

In summary, the present study provides evidence of dynamic migratory and proliferative behaviors of SVZ cells after stroke, which lends valuable insight into the mechanisms underlying stroke-induced neurogenesis in the adult brain.

\section{References}

Arvidsson A, Collin T, Kirik D, Kokaia Z, Lindvall O (2002) Neuronal replacement from endogenous precursors in the adult brain after stroke. Nat Med 8:963-970.

Chiasson BJ, Tropepe V, Morshead CM, van der Kooy D (1999) Adult mammalian forebrain ependymal and subependymal cells demonstrate proliferative potential, but only subependymal cells have neural stem cell characteristics. J Neurosci 19:4462-4471.

Doetsch F, Garcia-Verdugo JM, Alvarez-Buylla A (1997) Cellular composition and three-dimensional organization of the subventricular germinal zone in the adult mammalian brain. J Neurosci 17:5046-5061.

Edmondson JC, Hatten ME (1987) Glial-guided granule neuron migration in vitro: a high-resolution time-lapse video microscopic study. J Neurosci $7: 1928-1934$

Feng Y, Walsh CA (2001) Protein-protein interactions, cytoskeletal regulation and neuronal migration. Nat Rev Neurosci 2:408-416.

Garcia-Verdugo JM, Doetsch F, Wichterle H, Lim DA, Alvarez-Buylla A (1998) Architecture and cell types of the adult subventricular zone: in search of the stem cells. J Neurobiol 36:234-248.

Imitola J, Raddassi K, Park KI, Mueller FJ, Nieto M, Teng YD, Frenkel D, Li J, Sidman RL, Walsh CA, Snyder EY, Khoury SJ (2004) Directed migration of neural stem cells to sites of CNS injury by the stromal cell-derived factor 1alpha/CXC chemokine receptor 4 pathway. Proc Natl Acad Sci USA 101:18117-18122.

Jin K, Sun Y, Xie L, Peel A, Mao XO, Batteur S, Greenberg DA (2003) Directed migration of neuronal precursors into the ischemic cerebral cortex and striatum. Mol Cell Neurosci 24:171-189.

Lee SR, Kim HY, Rogowska J, Zhao BQ, Bhide P, Parent JM, Lo EH (2006) Involvement of matrix metalloproteinase in neuroblast cell migration from the subventricular zone after stroke. J Neurosci 26:3491-3495.

Levison SW, Goldman JE (1993) Both oligodendrocytes and astrocytes develop from progenitors in the subventricular zone of postnatal rat forebrain. Neuron 10:201-212.

Lindvall O, Kokaia Z, Martinez-Serrano A (2004) Stem cell therapy for human neurodegenerative disorders-how to make it work. Nat Med [Suppl] $10: S 42-S 50$

Luskin MB, Zigova T, Soteres BJ, Stewart RR (1997) Neuronal progenitor cells derived from the anterior subventricular zone of the neonatal rat forebrain continue to proliferate in vitro and express a neuronal phenotype. Mol Cell Neurosci 8:351-366.

Menezes JR, Smith CM, Nelson KC, Luskin MB (1995) The division of neuronal progenitor cells during migration in the neonatal mammalian forebrain. Mol Cell Neurosci 6:496-508.
Miyata T, Kawaguchi A, Saito K, Kuramochi H, Ogawa M (2002) Visualization of cell cycling by an improvement in slice culture methods. J Neurosci Res 69:861-868.

Morshead CM, Reynolds BA, Craig CG, McBurney MW, Staines WA, Morassutti D, Weiss S, van der Kooy D (1994) Neural stem cells in the adult mammalian forebrain: a relatively quiescent subpopulation of subependymal cells. Neuron 13:1071-1082.

Noctor SC, Martinez-Cerdeno V, Ivic L, Kriegstein AR (2004) Cortical neurons arise in symmetric and asymmetric division zones and migrate through specific phases. Nat Neurosci 7:136-144.

Parent JM, Vexler ZS, Gong C, Derugin N, Ferriero DM (2002) Rat forebrain neurogenesis and striatal neuron replacement after focal stroke. Ann Neurol 52:802-813.

Paxinos G, Watson C (1986) The rat brain in stereotaxic coordinates, Ed 2. New York: Academic.

Robin AM, Zhang ZG, Wang L, Zhang RL, Katakowski M, Zhang L, Wang Y, Zhang C, Chopp M (2006) Stromal cell-derived factor lalpha mediates neural progenitor cell motility after focal cerebral ischemia. J Cereb Blood Flow Metab 26:125-134.

Suzuki SO, Goldman JE (2003) Multiple cell populations in the early postnatal subventricular zone take distinct migratory pathways: a dynamic study of glial and neuronal progenitor migration. J Neurosci 23:4240-4250.

Thored P, Arvidsson A, Cacci E, Ahlenius H, Kallur T, Darsalia V, Ekdahl CT, Kokaia Z, Lindvall O (2006) Persistent production of neurons from adult brain stem cells during recovery after stroke. Stem Cells 24:739-747.

Wang L, Zhang ZG, Zhang RL, Gregg SR, Hozeska-Solgot A, LeTourneau Y, Wang Y, Chopp M (2006) Matrix metalloproteinase 2 (MMP2) and MMP9 secreted by erythropoietin-activated endothelial cells promote neural progenitor cell migration. J Neurosci 26:5996-6003.

Wichterle H, Garcia-Verdugo JM, Alvarez-Buylla A (1997) Direct evidence for homotypic, glia-independent neuronal migration. Neuron 18:779-791.

Yamashita T, Ninomiya M, Hernandez Acosta P, Garcia-Verdugo JM, Sunabori T, Sakaguchi M, Adachi K, Kojima T, Hirota Y, Kawase T, Araki N, Abe K, Okano H, Sawamoto K (2006) Subventricular zone-derived neuroblasts migrate and differentiate into mature neurons in the post-stroke adult striatum. J Neurosci 26:6627-6636.

Zhang R, Zhang Z, Wang L, Wang Y, Gousev A, Zhang L, Ho KL, Morshead C, Chopp M (2004a) Activated neural stem cells contribute to strokeinduced neurogenesis and neuroblast migration toward the infarct boundary in adult rats. J Cereb Blood Flow Metab 24:441-448.

Zhang R, Zhang Z, Zhang C, Zhang L, Robin A, Wang Y, Lu M, Chopp M (2004b) Stroke transiently increases subventricular zone cell division from asymmetric to symmetric and increases neuronal differentiation in the adult rat. J Neurosci 24:5810-5815.

Zhang RL, Chopp M, Zhang ZG, Jiang Q, Ewing JR (1997) A rat model of embolic focal cerebral ischemia. Brain Res 766:83-92.

Zhang RL, Zhang ZG, Zhang L, Chopp M (2001) Proliferation and differentiation of progenitor cells in the cortex and the subventricular zone in the adult rat after focal cerebral ischemia. Neuroscience 105:33-41.

Zhang RL, Zhang L, Zhang ZG, Morris D, Jiang Q, Wang L, Zhang LJ, Chopp M (2003) Migration and differentiation of adult rat subventricular zone progenitor cells transplanted into the adult rat striatum. Neuroscience 116:373-382.

Zhang RL, Zhang ZG, Lu M, Wang Y, Yang JJ, Chopp M (2006) Reduction of the cell cycle length by decreasing $G(1)$ phase and cell cycle reentry expand neuronal progenitor cells in the subventricular zone of adult rat after stroke. J Cereb Blood Flow Metab 26:857-863. 